\title{
ASIA AND \\ INTERNATIONAL ORGANIZATIONS
}

